\title{
The Contribution of MMP-7 Promoter Polymorphisms in Renal Cell Carcinoma
}

\author{
CHENG-HSI LIAO ${ }^{1,2,3^{*}}$, WEN-SHIN CHANG ${ }^{4 *}$, PEI-SHIN HU ${ }^{*}$, HSI-CHIN WU ${ }^{4}$, SHIH-WEI HSU ${ }^{1,2,3}$, \\ YEN-FANG LIU ${ }^{4}$, SHIH-PING LIU ${ }^{1}$, HUEY-SHAN HUNG ${ }^{1}$, DA-TIAN BAU ${ }^{1,4,6}$ and CHIA-WEN TSAI ${ }^{4}$ \\ ${ }^{1}$ Graduate Institute of Biomedical Sciences, China Medical University, Taichung, Taiwan, R.O.C.; \\ ${ }^{2}$ Taichung Armed Forces General Hospital, Taichung, Taiwan, R.O.C.; \\ ${ }^{3}$ National Defense Medical Center, Taipei, Taiwan, R.O.C.; \\ ${ }^{4}$ Terry Fox Cancer Research Laboratory, China Medical University Hospital, Taichung, Taiwan, R.O.C.; \\ ${ }^{5}$ Department of Ophthalmology, Changhua Christian Hospital, Changhua, Taiwan, R.O.C.; \\ ${ }^{6}$ Department of Bioinformatics and Medical Engineering, Asia University, Taichung, Taiwan, R.O.C.
}

\begin{abstract}
Background/Aim: Mounting evidence has suggested that polymorphisms in the promoters of matrix metalloproteinase (MMP) genes are associated with the risk of many types of cancer, but no study has ever explored these polymorphisms as biomarkers for renal cell cancer (RCC). Recently, it was suggested that serum MMP-7 levels have both diagnostic and prognostic potential for RCC. In this study, we focused on the contribution of two functional polymorphisms in the promoter region of MMP-7 (A-181G and C-153T) to RCC. Materials and Methods: These two polymorphisms were genotyped in 92 patients with RCC and 580 controls by PRCRFLP analysis. Results: The results showed that there is no significant association of the RCC risk with the MMP-7 A-181G genotype, even after adjusted for the possible confounding factors. The MMP-7 C-153T polymorphism was not identified among the subjects investigated. Conclusion: Our findings suggest that the two MMP-7 polymorphisms A$181 G$ and $C-153 T$ do not play a major role in determining personal susceptibility to RCC in Taiwan.
\end{abstract}

To date, there is no recommended biomarker available for the prediction of renal cell cancer (RCC). RCC has a 209,000 worldwide annual incidence which continues to rise

This article is freely accessible online.

*These Authors contributed equally to this study.

Correspondence to: Da-Tian Bau and Chia-Wen Tsai, Terry Fox Cancer Research Laboratory, China Medical University Hospital, 2 Yuh-Der Road, Taichung, 404 Taiwan, R.O.C. Tel: +886 422052121 Ext.7534, e-mail: datian@mail.cmuh.org.tw; artbau2@gmail.com

Key Words: Genotype, MMP-7, polymorphism, renal cell cancer, Taiwan. $\sim 2 \%$ each year (1). Many RCCs remain asymptomatic even in advanced tumor stages $(1,2)$ and even worse, up to $30 \%$ of patients treated by radical nephrectomy will relapse (3). Current prognostication is mainly based on histological validations that may consume great amount of manpower and time but frequently do no help in determining the therapy and medication. Therefore, molecular markers for early detection are urgently needed.

The matrix metalloproteinases (MMP) are a family of enzymes which are in charge of the degradation of a wide spectrum of extracellular matrix and non-matrix proteins during both physiologic and pathologic states $(4,5)$. During carcinogenesis, MMPs can regulate the microenvironment and contribute to several critical steps in cancer development via their involvement in cell proliferation, differentiation, apoptosis, invasion, migration, metastasis, angiogenesis, and immune surveillance (6). In literature, there is mounting evidence indicating that functional polymorphisms of $M M P s$ may contribute to inter-individual differences in susceptibility to several types of cancer (7-14).

The current study aimed at investigating the contribution of two MMP-7 promoter polymorphisms, A-181G and C$153 \mathrm{~T}$, to the susceptibility of RCC in Taiwan. In a promoter assay, the basal promoter activity was higher in promoter constructs harboring the combination of the two rare alleles of A-181G and C-153T (15). In literature, the A-181G genotype of $M M P-7$ was reported to be associated with oral, esophageal, gastric, colorectal, lung and ovarian cancers. However the role of MMP-7 genotypes has never been studied in RCC previously.

\section{Materials and Methods}

Patients and controls. The hospital-based case-control study recruited 92 RCC patients and 580 cancer-free controls matched by age and 
in vivo $31: 631-635$ (2017)

Table I. Distributions of the frequencies of selected characteristics among the RCC cases and healthy controls.

\begin{tabular}{|c|c|c|c|c|c|}
\hline \multirow[t]{2}{*}{ Characteristics } & \multicolumn{2}{|c|}{ Cases $(n=92)$} & \multicolumn{2}{|c|}{ Controls $(\mathrm{n}=580)$} & \multirow[t]{2}{*}{$p$-Value } \\
\hline & $\mathrm{N}$ & $\%$ & $\mathrm{~N}$ & $\%$ & \\
\hline Age (year) $($ mean $\pm S D)$ & $58.8 \pm 11.7$ & & $58.3 \pm 11.5$ & & 0.8971 \\
\hline$<60$ & 47 & $51.1 \%$ & 307 & $52.9 \%$ & 0.8223 \\
\hline$>60$ & 45 & $48.9 \%$ & 273 & $47.1 \%$ & \\
\hline \multicolumn{6}{|l|}{ Gender } \\
\hline Male & 59 & $64.1 \%$ & 371 & $64.0 \%$ & 1.0000 \\
\hline Female & 33 & $35.9 \%$ & 209 & $36.0 \%$ & \\
\hline \multicolumn{6}{|l|}{ Smoking status } \\
\hline Smokers & 41 & $44.6 \%$ & 220 & $37.9 \%$ & 0.2499 \\
\hline Non-smokers & 51 & $55.4 \%$ & 360 & $62.1 \%$ & \\
\hline \multicolumn{6}{|l|}{ Alcohol drinking status } \\
\hline Drinkers & 37 & $40.2 \%$ & 209 & $36.0 \%$ & 0.4848 \\
\hline Non-drinkers & 55 & $59.8 \%$ & 371 & $64.0 \%$ & \\
\hline \multicolumn{6}{|l|}{ Hypertension } \\
\hline Yes & 61 & $66.3 \%$ & 302 & $52.1 \%$ & $0.0130 *$ \\
\hline No & 31 & $33.7 \%$ & 278 & $47.9 \%$ & \\
\hline \multicolumn{6}{|l|}{ Diabetes } \\
\hline Yes & 21 & $22.8 \%$ & 104 & $17.9 \%$ & 0.2523 \\
\hline No & 71 & $77.2 \%$ & 476 & $82.1 \%$ & \\
\hline \multicolumn{6}{|l|}{ Family cancer history } \\
\hline Yes & 6 & $6.5 \%$ & 17 & $2.9 \%$ & 0.1125 \\
\hline No & 86 & $93.5 \%$ & 563 & $97.1 \%$ & \\
\hline
\end{tabular}

*Statistically significant.

gender, while none of the participants were related to each other by any biological relationship. RCC in all subjects in the patient group was diagnosed and histopathologically confirmed by the surgeons, and no patient had a prior history of any other cancer. Also, the age- and gender-matched cancer-free controls were genetically unrelated to any of the RCC patients and had no individual history of cancer. A further exclusion criterion for the controls was symptoms suggestive of RCC, such as hematuria. Each subject in this study was required to provide 3-5 $\mathrm{ml}$ of venous blood after their full understanding of the project and providing their written informed consent. The study was approved by the Institutional Review Board of China Medical University and kindly helped with the tissue bank of China Medical University Hospital. The selected characteristics of the control and patient groups are summarized and compared in Table I.

Methodology of MMP-7 genotyping. Total genomic DNA of each participant was extracted from blood leukocytes and stored as previously described (16-18). Briefly, the polymerase chain reaction (PCR) cycling conditions were: one cycle at $94^{\circ} \mathrm{C}$ for $5 \mathrm{~min} ; 35$ cycles of $94^{\circ} \mathrm{C}$ for $30 \mathrm{sec}, 59^{\circ} \mathrm{C}$ for $30 \mathrm{sec}$ and $72^{\circ} \mathrm{C}$ for $30 \mathrm{sec}$, and a final extension at $72^{\circ} \mathrm{C}$ for $10 \mathrm{~min}$. The PCR for $M M P-7 \mathrm{~A}-181 \mathrm{G}$ was conducted using the forward primer 5'-TGGTACCATAATGT CCTGAATG-3', and the reverse primer 5'-TCGTTATTGG CAGGAAGCACACAATGAATT-3'. The obtained 150bp PCR product was digested with $E c o R I$ and resulted in two fragments of 120 and $30 \mathrm{bp}$ when $\mathrm{G}$ allele was present, while in the presence of the A allele the $150 \mathrm{bp}$ fragment remained intact. As for MMP-7 C153T, direct sequencing PCR was conducted with the same primers as for $M M P-7 \mathrm{~A}-181 \mathrm{G}$.
Statistical analysis. To ensure that the controls used were representative of the general population and to exclude the possibility of a genotyping error, the deviation of the genotype frequencies of $M M P-7$ polymorphisms in the control subjects from those expected under the Hardy-Weinberg equilibrium was assessed using the goodness-of-fit test. Pearson's Chi-square test or Fisher's exact test (when the expected number in any cell was less than five) was used to compare the distribution of the $M M P-7$ genotypes between case and control groups. The associations between the $M M P-7$ polymorphisms and RCC risk were estimated by computing Odds ratios (ORs) and their $95 \%$ confidence intervals (95\%CIs) from unconditional logistic regression analysis with the adjustment for possible confounders.

\section{Results}

Basic characteristic factors compared between the RCC case and control groups. The frequency distributions of the characteristic factors for RCC among the control and case subjects are summarized in Table I. There were no differences between the two groups regarding age, gender, smoking or alcohol drinking status, diabetes or family history of cancer $(p>0.05)$. However, there were $66.3 \%$ of subjects with hypertension among the RCC cases and $52.1 \%$ among the controls, and the difference is statistically significant $(p=0.013)$.

Association of MMP-7 genotypes and RCC risk. The distribution of genetic frequencies for the $M M P-7$ 
polymorphisms in the RCC cases and controls are presented and compared in Table II. First, there was no polymorphic genotype at MMP-7 C-153T found among either the cases or the controls (Table II, lower panel). Second, the ORs with adjusting those possible confounding factors (age, gender, smoking, alcohol drinking, hypertension, diabetes and family cancer history status) for the people carrying AG and GG genotypes at MMP-7 promoter A-181G were $1.13(95 \%$ $\mathrm{CI}=0.53-2.01, p=0.6668)$ and $1.43(95 \% \mathrm{CI}=0.18-11.63$, $p=0.6698$ ) respectively, compared to those carrying the AA wild-type genotype (Table II, upper panel). The $p$ for trend was not significant $(p=0.8375)$ (Table II). In the dominant model (AG plus GG versus AA), the association between $M M P-7$ promoter A-181G polymorphism and the risk for RCC was also not statistically significant $(\mathrm{OR}=1.19,95 \%$ $\mathrm{CI}=0.58-2.17, p=0.6028$ ) (Table II). To sum up, these data indicated that either A or $\mathrm{G}$ allele at $M M P-7 \mathrm{~A}-181 \mathrm{G}$ may not play a critical role for determining the risk of RCC in Taiwan (Table III).

Association of MMP-7 allelic types and RCC risk. The adjusted $\mathrm{OR}$ for the subjects carrying the $\mathrm{G}$ allele at $M M P-7$ promoter A-181G was $1.37(95 \% \mathrm{CI}=0.69-2.05, p=0.5493)$, compared to those carrying the A wild-type allele (Table III). Consistent with the findings in Table II, there is no differential distribution of allelic frequencies between RCC case and control groups as for the MMP-7 promoter A-181G (Table III).

\section{Discussion}

In the literature, promoter SNPs of $M M P$ genes have been strongly associated with the risk of several types of cancers (7-14), but currently it remains unknown whether any polymorphism in MMPs can act as a risk factor for the development of RCC. In the present study, we examined the genotypes of MMP-7 among a Taiwanese population, and assessed whether there was an association between the genotypes of $M M P-7 \mathrm{~A}-181 \mathrm{G}$ and $M M P-7 \mathrm{C}-153 \mathrm{~T}$ with RCC risk. The results showed that no significant association was observed in this hospital-based case-control population. Our findings suggest that these two $M M P-7$ genotypes may not play a critical role in mediating susceptibility to RCC.

The rational for focusing on the MMP-7 promoter polymorphisms, A-181G and C-153T, is based on the phenotypic findings which report that MMP-7 may serve as a promising serum marker for the prediction of RCC (19-21). In 2008, Sarkissian and his colleagues examined the serum levels of MMP-7 among healthy subjects, control patients and 30 RCC patients and found that MMP-7 was significantly higher in RCC patients than the other two groups (19). In the same year, Ramankulov and his colleagues reported that similar MMP-7 levels were found in controls and patients with non-metastatic RCCs , while
Table II. Distributions of matrix metalloproteinase-7 (MMP-7) genotypic frequencies among the RCC cases and controls.

\begin{tabular}{lcccc}
\hline & $\begin{array}{c}\text { RCC } \\
\text { cases }(\%)\end{array}$ & $\begin{array}{c}\text { Controls } \\
(\%)\end{array}$ & $\begin{array}{c}\text { Adjusted OR } \\
(95 \% \mathrm{CI})^{\mathrm{a}}\end{array}$ & $p$-Value \\
\hline A-181G & & & & \\
AA & $81(88.0)$ & $521(89.8)$ & 1.00 (reference) & \\
AG & $10(10.9)$ & $55(9.5)$ & $1.13(0.53-2.01)$ & 0.6668 \\
GG & $1(1.1)$ & $4(0.7)$ & $1.43(0.18-11.63)$ & 0.6698 \\
AG+GG & $11(12.0)$ & $59(10.2)$ & $1.19(0.58-2.17)$ & 0.6028 \\
$p_{\text {trend }}$ & & & & 0.8375 \\
C-153T & & & -00 (reference) & \\
CC & $92(100.0)$ & $580(100.0)$ & -- & \\
CT & $0(0.0)$ & $0(0.0)$ & -- & \\
TT & $0(0.0)$ & $0(0.0)$ & & \\
$p_{\text {trend }}$ & & & & \\
\hline
\end{tabular}

OR: Odds ratio; CI: confidence interval. aData have been adjusted with confounding factors including age, gender, smoking, drinking status, hypertension, diabetes and family history of cancer. bBased on Chisquare test without Yates' correction or Fisher's exact test; * $p<0.05$.

Table III. Allelic frequencies for matrix metalloproteinase-7 (MMP-7) polymorphisms in the RCC and control groups.

\begin{tabular}{lcccc}
\hline $\begin{array}{l}\text { Polymorphic } \\
\text { site } \\
\text { Allele }\end{array}$ & $\begin{array}{c}\text { RCC } \\
\text { cases }(\%) \\
\mathrm{N}=184\end{array}$ & $\begin{array}{c}\text { Controls } \\
(\%) \\
\mathrm{N}=1160\end{array}$ & $\begin{array}{c}\text { Adjusted OR } \\
(95 \% \mathrm{CI})^{\mathrm{a}}\end{array}$ & $p$-Value \\
\hline A-181G & & & & \\
$\quad$ Allele A & $172(93.5)$ & $1097(94.6)$ & 1.00 (reference) & 0.5493 \\
Allele G & $12(6.5)$ & $63(5.4)$ & $1.37(0.69-2.05)$ & \\
C-153T & & & & \\
Allele C & $184(100.0)$ & $1160(100.0)$ & 1.00 (reference) & \\
Allele T & $0(0.0)$ & $0(0.0)$ & -- & \\
\hline
\end{tabular}

OR: Odds ratio; CI: confidence interval. aData that have been adjusted with confounding factors include age, gender, smoking, drinking status, hypertension, diabetes and family history of cancer. ${ }^{b}$ Based on Chisquare test without Yates' correction or Fisher's exact test; $* p<0.05$.

MMP-7 serum levels were significantly elevated in metastatic RCCs. In addition, high MMP-7 levels were independently associated with shorter disease-specific survival. The authors suggested that serum MMP-7 may serve as a marker of metastasis and poor prognosis but not as a diagnostic marker (20). In 2016, Niedworok and his colleagues' findings also showed elevated serum levels in metastatic compared to non-metastatic RCC cases (19). Thus, MMP-7, in addition to carbonic anhydrase IX, VEGF, IL-6 and CRP, may serve as a promising serum marker for the detection of metastasis and prediction of poor survival for RCC, similarly to other cancers including gastric (22), colorectal $(23,24)$ and ovarian cancer $(25)$. 
There are several limitations in this study. First, the small number of samples used in the study may be an explanation for negative findings. Additional larger case-control studies are warranted to understand the roles of $M M P-7$ genotypes in the etiology of RCC. Second, we could not exclude the possibility of inherent selection bias. As a hospital-based study, our RCC cases were enrolled from our hospital and the control subjects were selected from the local community population. Thus, inherent selection bias cannot be completely excluded and population-based studies are needed. Third, the MMPs are differentially regulated and expressed according to the status of microenvironment during carcinogenesis, which is very complicated. As discussed above, the expression of MMP-7 was higher in patients with metastatic RCC, than in patients without. The phenotypic data such as the expression levels at mRNA and protein examined from the tissues of the investigated subjects are not currently available for our further analysis. The complete correlation of patient status, genotype and phenotype would be very helpful to understand the role of MMP-7 in RCC.

In conclusion, this is the first study to investigate the role of MMP-7 genotypes in RCC. Our results suggest that the promoter polymorphisms of $M M P-7, \mathrm{~A}-181 \mathrm{G}$ and C-153T, do not significantly confer susceptibility to RCC in the Taiwan population studied. Additional studies for the genotypes of other members of $M M P$ family and their associations with RCC risk are warranted before the contribution of $M M P$ genotypes to RCC can be fully ascertained.

\section{Conflicts of Interest}

The Authors declare no conflicts of interest.

\section{Acknowledgements}

The Authors would like to thank Hsin-Ting Li and Shiou-Ting Yen for their excellent technical assistance. All the participants in this study are appreciated. This study was supported mainly by Taichung Armed Forces General Hospital to Dr. Liao (supporting number 106-A16) and partially by research grant from Taiwan Ministry of Health and Welfare Clinical Trial and Research Center of Excellence (MOHW106-TDU-B-212-113004). The funders had no role in study design, data collection and analysis, decision to publish or preparation of the manuscript.

\section{References}

1 Ferlay J, Shin HR, Bray F, Forman D, Mathers C and Parkin DM: Estimates of worldwide burden of cancer in 2008: GLOBOCAN 2008. Int J Cancer 127: 2893-2917, 2010.

2 Niedworok C, Dorrenhaus B, Vom Dorp F, Piotrowski JA, Tschirdewahn S, Szarvas T, Rubben H and Schenck M: Renal cell carcinoma and tumour thrombus in the inferior vena cava: clinical outcome of 98 consecutive patients and the prognostic value of preoperative parameters. World J Urol 33: 1541-1552, 2015.

3 Cohen HT and McGovern FJ: Renal-cell carcinoma. N Engl J Med 353: 2477-2490, 2005.

4 Werb Z: ECM and cell surface proteolysis: regulating cellular ecology. Cell 91: 439-442, 1997.

5 Sternlicht MD and Werb Z: How matrix metalloproteinases regulate cell behavior. Annu Rev Cell Dev Biol 17: 463-516, 2001.

6 Egeblad $M$ and Werb $Z$ : New functions for the matrix metalloproteinases in cancer progression. Nat Rev Cancer 2: 161-174, 2002.

7 Tsai CW, Chang WS, Gong CL, Shih LC, Chen LY, Lin EY, Li $\mathrm{HT}$, Yen ST, Wu CN and Bau DT: Contribution of Matrix Metallopeptidase-1 Genotypes, Smoking, Alcohol Drinking and Areca Chewing to Nasopharyngeal Carcinoma Susceptibility. Anticancer Res 36: 3335-3340, 2016.

8 Sun KT, Tsai CW, Chang WS, Shih LC, Chen LY, Tsai MH, Ji HX, Hsiao CL, Liu YC, Li CY and Bau DT: The Contribution of Matrix Metalloproteinase-1 Genotype to Oral Cancer Susceptibility in Taiwan. In Vivo 30: 439-444, 2016.

9 Ye S: Polymorphism in matrix metalloproteinase gene promoters: implication in regulation of gene expression and susceptibility of various diseases. Matrix Biol 19: 623-629, 2000.

10 Price SJ, Greaves DR and Watkins H: Identification of novel, functional genetic variants in the human matrix metalloproteinase2 gene: role of $\mathrm{Sp} 1$ in allele-specific transcriptional regulation. J Biol Chem 276: 7549-7558, 2001.

11 Yu C, Zhou Y, Miao X, Xiong P, Tan W and Lin D: Functional haplotypes in the promoter of matrix metalloproteinase- 2 predict risk of the occurrence and metastasis of esophageal cancer. Cancer Res 64: 7622-7628, 2004.

12 Elander N, Soderkvist P and Fransen K: Matrix metalloproteinase (MMP) -1, -2, -3 and -9 promoter polymorphisms in colorectal cancer. Anticancer Res 26: 791-795, 2006.

13 Li Y, Jin X, Kang S, Wang Y, Du H, Zhang J, Guo W, Wang N and Fang S: Polymorphisms in the promoter regions of the matrix metalloproteinases-1, $-3,-7$, and -9 and the risk of epithelial ovarian cancer in China. Gynecol Oncol 101: 92-96, 2006.

14 Hu Z, Huo X, Lu D, Qian J, Zhou J, Chen Y, Xu L, Ma H, Zhu J, Wei $Q$ and Shen H: Functional polymorphisms of matrix metalloproteinase-9 are associated with risk of occurrence and metastasis of lung cancer. Clin Cancer Res 11: 5433-5439, 2005.

15 Jormsjo S, Whatling C, Walter DH, Zeiher AM, Hamsten A and Eriksson P: Allele-specific regulation of matrix metalloproteinase7 promoter activity is associated with coronary artery luminal dimensions among hypercholesterolemic patients. Arterioscler Thromb Vasc Biol 21: 1834-1839, 2001.

16 Chang WS, Liao CH, Miao CE, Wu HC, Hou LL, Hsiao CL, Ji $\mathrm{HX}$, Tsai CW and Bau DT: The role of functional polymorphisms of cyclooxygenase 2 in renal cell carcinoma. Anticancer Res 34: 5481-5486, 2014.

17 Lo WJ, Chang WS, Hsu HF, Ji HX, Hsiao CL, Tsai CW, Yeh SP, Chen CM and Bau DT: Significant Association of Interleukin-10 Polymorphisms with Childhood Leukemia Susceptibility in Taiwan. In Vivo 30: 265-269, 2016.

18 Chang WS, Liao CH, Tsai CW, Hu PS, Wu HC, Hsu SW, Ji HX, Hsiao CL and Bau DT: The Role of IL-10 Promoter Polymorphisms in Renal Cell Carcinoma. Anticancer Res 36: 2205-2209, 2016. 
19 Sarkissian G, Fergelot P, Lamy PJ, Patard JJ, Culine S, Jouin P, Rioux-Leclercq N and Darbouret B: Identification of pro-MMP7 as a serum marker for renal cell carcinoma by use of proteomic analysis. Clin Chem 54: 574-581, 2008.

20 Ramankulov A, Lein M, Johannsen M, Schrader M, Miller K and Jung K: Plasma matrix metalloproteinase-7 as a metastatic marker and survival predictor in patients with renal cell carcinomas. Cancer Sci 99: 1188-1194, 2008.

21 Niedworok C, vom Dorp F, Tschirdewahn S, Rubben H, Reis H, Szucs $M$ and Szarvas T: Validation of the diagnostic and prognostic relevance of serum MMP-7 levels in renal cell cancer by using a novel automated fluorescent immunoassay method. Int Urol Nephrol 48: 355-361, 2016.

22 Sentani K, Matsuda M, Oue N, Uraoka N, Naito Y, Sakamoto N and Yasui W: Clinicopathological significance of MMP-7, laminin gamma2 and EGFR expression at the invasive front of gastric carcinoma. Gastric Cancer 17: 412-422, 2014.
23 Martinez-Fernandez A, Garcia-Albeniz X, Pineda E, Visa L, Gallego R, Codony-Servat J, Auge JM, Longaron R, Gascon P, Lacy A, Castells A and Maurel J: Serum matrilysin levels predict outcome in curatively resected colorectal cancer patients. Ann Surg Oncol 16: 1412-1420, 2009.

24 Sun DW, Zhang YY, Qi Y, Zhou XT and Lv GY: Prognostic significance of MMP-7 expression in colorectal cancer: a metaanalysis. Cancer Epidemiol 39: 135-142, 2015.

25 Acar A, Onan A, Coskun U, Uner A, Bagriacik U, Atalay F, Unsal DK and Guner H: Clinical significance of serum MMP-2 and MMP-7 in patients with ovarian cancer. Med Oncol 25: 279$283,2008$.

Received April 14, 2017

Revised May 1, 2017

Accepted May 2, 2017 